\title{
A COMPARISON OF MULTIPLE STEP AND SINGLE STEP METHODS FOR DETERMINING CYCLIC STRESS-STRAIN RELATIONSHIP FOR TWO NON-MASING MATERIALS
}

\author{
L. Pejkowski*
}

\begin{abstract}
Two ferritic-pearlitic steel grades were tested using single and multiple step methods of determination of cyclic stress-strain relationship. Both materials exhibit a change from Masing to nonMasing hysteretic behavior at some strain level, when subjected to multiple step method. In case of single step method only non-Masing behavior was observed. Despite that, it was shown that using the multiple step method, which is less accurate than single step one, can give very satisfactory results. The stress-strain curves were described using the master curve method, since the commonly used Ramberg-Osgood equation cannot be used for non-Masing materials.
\end{abstract}

Keywords: low-cycle fatigue, strain-hysteresis loops, non-Masing behavior, stress-strain relationship

\section{Introduction}

The complexity of the phenomenon of fatigue degradation of materials results in many models used in various design situations. For example, a different approach is necessary in case of random loading (Kurek et al., 2017), block loading (Skibicki et al., 2014) or non-proportional loading (Pejkowski, 2017). Most of models require determination of specific material parameters (Pejkowski and Skibicki, 2015; Skibicki, 2007; Skibicki and Pejkowski, 2012). Many of methods of determination of models' parameters require long-drawn fatigue tests, thus faster methods are being sought (Pejkowski et al., 2016; Skibicki et al., 2012).

One of the most frequently occurring design problem in fatigue of materials is modelling of cyclic stress-strain material response. The most popular method used for this purpose is description of hysteresis loops tips using Ramberg-Osgood equation (Ramberg and Osgood, 1943). The parameters of RambergOsgood relationship are widely used for example for calculation of plastic strain energy (Skibicki and Pejkowski, 2017). But the Ramberg-Osgood relationship can be used only in case of materials which exhibit the Masing behaviour.

For non-Masing materials, for which upper and lower branches of hysteresis loops cannot be described by the Ramberg-Osgood equation, the master curve method (Ellyin et al., 1991) can be used. This method can then be applied for calculation of plastic strain energy.

Determination of both Ramberg-Osgood and master curve parameters requires application of proper experimental procedure. The most accurate method is the single step fatigue test (Fig. 1 a), where mid-life hysteresis loops are used. But this method requires carrying out a full strain-controlled fatigue tests at few loading levels, which is expensive and time-consuming. For this reason, a few alternative and faster methods were developed (Ellyin, 1997). The most popular is the multiple test method, where the blocks of loading with increasing strain amplitude are applied (Fig. $1 \mathrm{~b}$ ). The big advantage of this method is that it can be used with one specimen only. But as an accelerated method it is burdened with a certain error.

Łukasz Pejkowski, PhD.: Faculty of Mechanical Engineering, University of Science and Technology, Kaliskiego 7; 85-796, Bydgoszcz; PL, 
In this work, both multiple and single step, strain-controlled fatigue tests were carried out for two steel grades and a comparison between the results is presented.
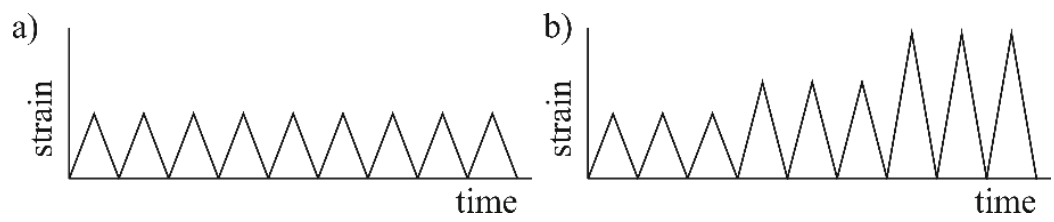

Fig. 1: Comparison of methods for determination of cyclic stress-strain curves a) single step method and b) multiple step method

\section{Materials and methods}

The fatigue strain-controlled tests were carried out on two steel grades: E235 (1.0308) and E355 (1.0580) after normalizing heat treatment. Both are non-alloy quality steels with ferritic-pearlitic microstructure. All tests were performed on Instron 8874 servo-hydraulic testing frame. For single step, as well as for multiple step method, 7 levels of strain amplitude were used: from $0.002 \mathrm{~mm} / \mathrm{mm}$ to $0.008 \mathrm{~mm} / \mathrm{mm}$, every $0.001 \mathrm{~mm} / \mathrm{mm}$. For multiple step method 100 cycles of loading were utilized for each block.

\section{Results}

In Fig. 2, the hysteresis loops for E235 steel are presented. For multiple step method, a change from Masing to non-Masing behavior can be observed, occurring between $0.004 \mathrm{~mm} / \mathrm{mm}$ and $0.005 \mathrm{~mm} / \mathrm{mm}$ strain amplitude levels. For single step method, material exhibits non-Masing behavior only. In case of both methods, for non-Masing hysteresis loops the strain hardening level is similar.
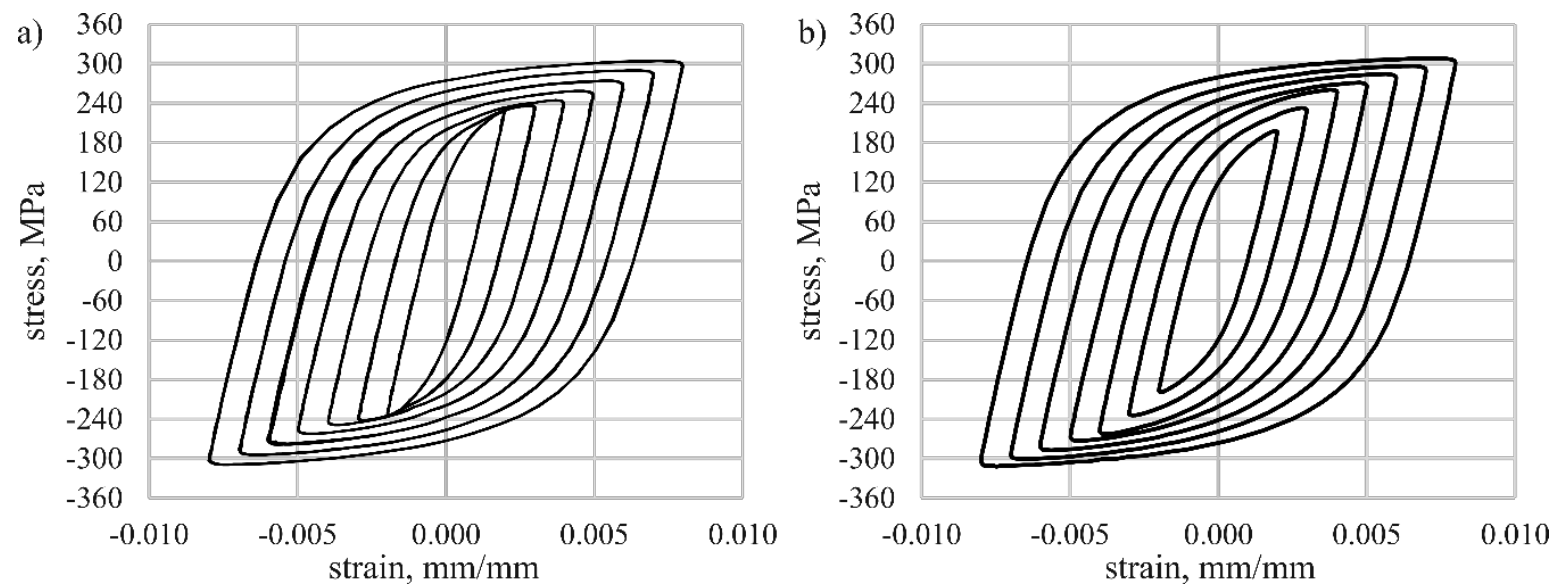

Fig. 2: Hysteresis loops for E235 steel a) for multiple step method b) for single step method

A very similar behavior can be observed in case of E355 steel (Fig. 3). The hysteresis loops behavior consistent with the Masing law appears up to $0.005 \mathrm{~mm} / \mathrm{mm}$ strain level. A slightly higher strain hardening occurs in case of single step method, due to lack of stabilization of stress response.
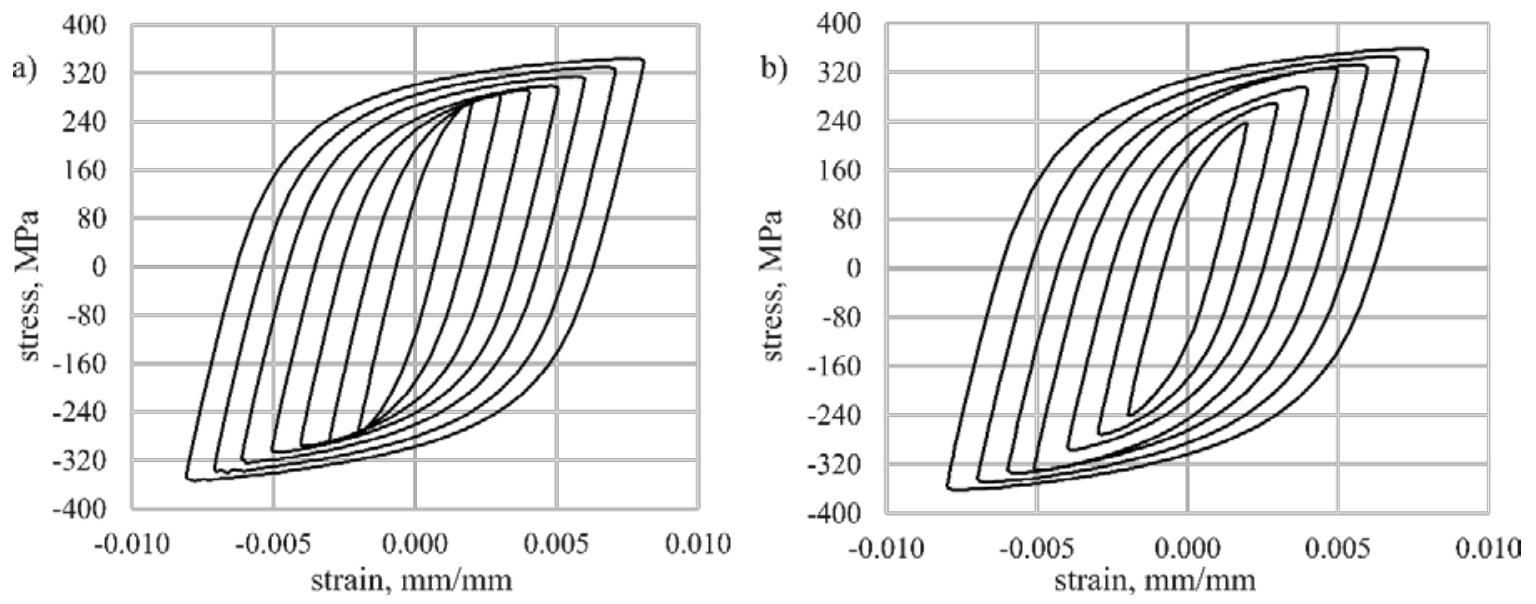

Fig. 3: Hysteresis loops for E355 steel a) for multiple step method b) for single step method 
Fig. 4 presents the procedure of determination of master curve. As an example, single step method for E235 steel was chosen. The procedure consists of matching the upper (tension) branches of the hysteresis loops by translation along the linear part. The same procedure was repeated for all four test groups.

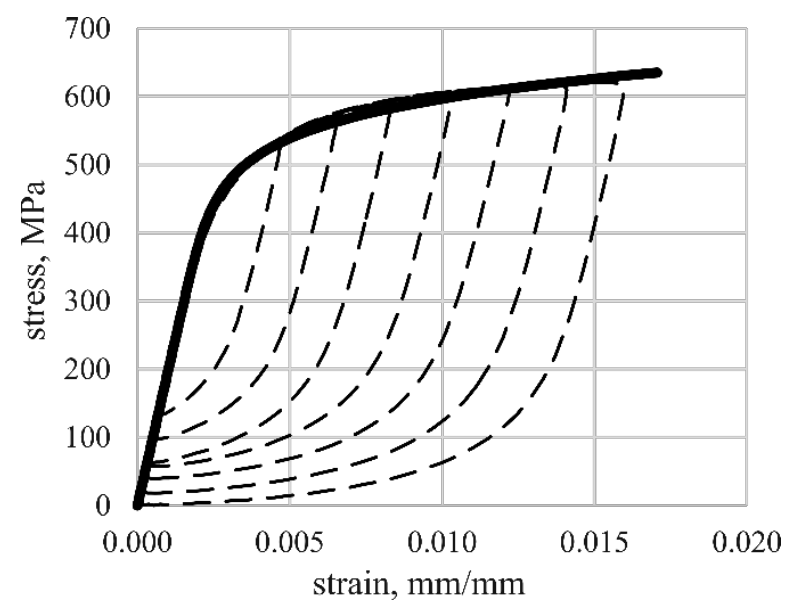

Fig. 4: Example of procedure of master curve determination

The master curve is described by the following equation (Ellyin, 1997):

$$
\Delta \varepsilon^{*}=\frac{\Delta \sigma^{*}}{E}+2\left(\frac{\Delta \sigma^{*}}{2 K^{*}}\right)^{\frac{1}{n^{*}}},
$$

where $\Delta \varepsilon^{*}$ is strain range, $\Delta \sigma^{*}$ is stress range, $E$ is Young modulus. $K^{*}$ and $n^{*}$ are found by fitting the experimental data. The asterisk superscript indicates the quantity is measured from origin $0^{*}$, which is equal to the lower tip of the hysteresis loop for the largest strain amplitude. Comparison for master curves determined using single and multiple step methods is presented in Fig. 5, and their constants are given in Tab. 1.

Tab. 1: Comparison of master curve parameters determined using single and multiple step methods

\begin{tabular}{|c|c|c|c|c|}
\hline & & $E$, GPa & $K^{*}, \mathrm{MPa}$ & $n^{*}$ \\
\hline \multirow{2}{*}{ E235 } & Single step method & \multirow{2}{*}{196.4} & 936.77 & 0.0908 \\
\hline & Multiple step method & & 806.19 & 0.062 \\
\hline \multirow{2}{*}{ E355 } & Single step method & \multirow{2}{*}{208.6} & 1201.5 & 0.1122 \\
\hline & Multiple step method & & 1203.1 & 0.1203 \\
\hline
\end{tabular}
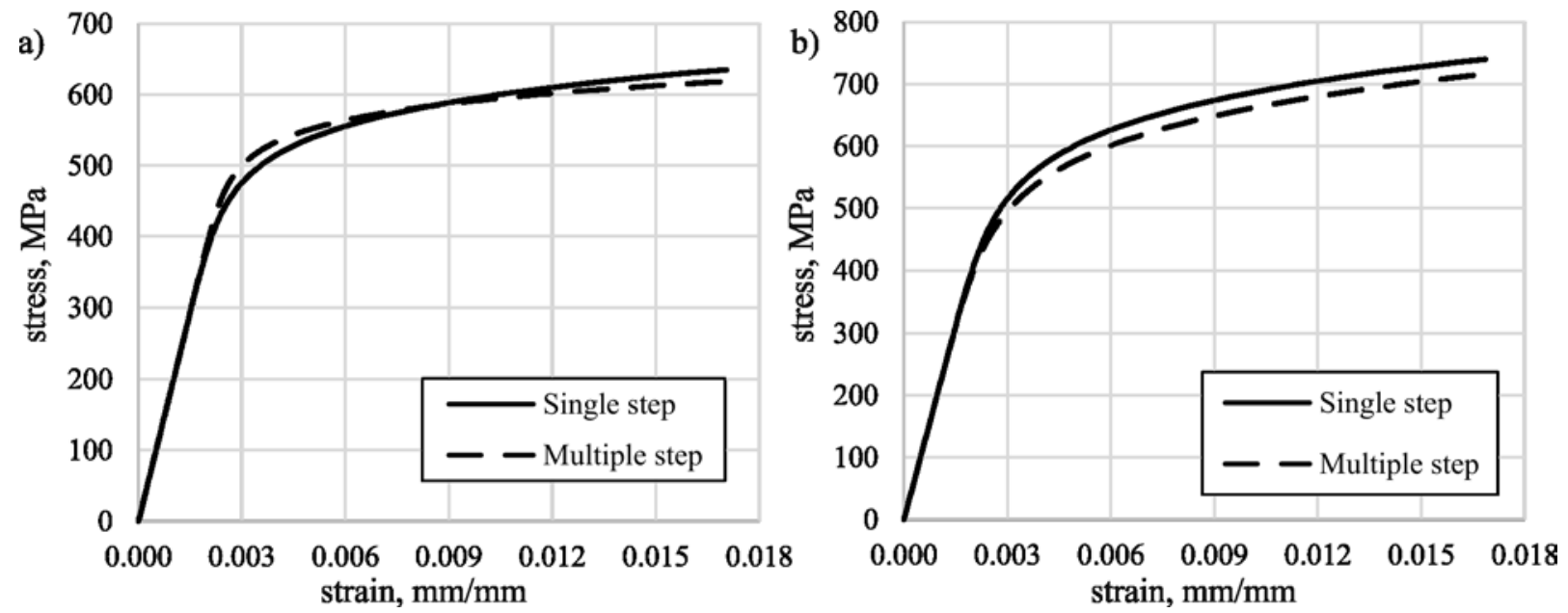

Fig. 5: Comparison of master curves determined using single and multiple step methods for a) E235 steel and b) E355 steel 


\section{Conclusions}

For the two tested steel grades the single step and multiple step methods of determination of cyclic stress-strain master curve gave very similar results. This conclusion is interesting, since these materials exhibit change from Masing to non-Masing behavior in multiple step method, while in case of single step method only non-Masing behavior occurs. One should notice, that proper determination of master curve by multiple step method can be made using higher strain amplitude levels only.

No significant change in strain hardening was observed for both methods. Thus, for materials similar to tested ones, the multiple step method can be considered as satisfactorily accurate.

\section{Acknowledgement}

This paper is realized within the framework of research project No. 2017/01/X/ST5/00143 funded by the National Science Centre in Poland.

\section{References}

Ellyin, F. (1997) Fatigue Damage, Crack Growth and Life Prediction. Chapman \& Hall.

Ellyin, F., Gołoś, K., Xia, Z. (1991) In Phase and Out-of-Phase Multiaxial Fatigue. Journal of Engineering Materials and Technology, 113, 1, pp. 112-118.

Kurek, M., Łagoda, T., Morel, F. (2017) Estimation of the Fatigue Life of 35NCD16 Alloy Steel Under Random Loading. Materials Science, 52, 4, pp. 492-499.

Pejkowski, Ł. (2017) On the material’s sensitivity to non-proportionality of fatigue loading. Archives of Civil and Mechanical Engineering, 7, 4, pp. 711-727.

Pejkowski, Ł., Skibicki, D. (2015) A criterion for high-cycle fatigue life and fatigue limit prediction in biaxial loading conditions. Acta Mechanica Sinica 32, 4, pp. 696-709.

Pejkowski, Ł., Skibicki, D., Lipski, A. (2016) Plastic strain energy of CuZn37 brass in low-cycle multiaxial fatigue regime, in: Fatigue Failure and Fracture Mechanics XXVI. AIP Conference Proceedings, Fojutowo, Poland, pp. 30004-1-30004-8.

Ramberg, W., Osgood, W.R. (1943) Description of stress-strain curves by three parameters, NACA-TN-902.

Skibicki, D. (2007) Experimental verification of fatigue loading nonproportionality model. Journal of Theoretical and Applied Mechanics 45, 2, pp. 337-348.

Skibicki, D., Pejkowski, Ł. (2017) Low-cycle multiaxial fatigue behaviour and fatigue life prediction for CuZn37 brass using the stress-strain models. International Journal of Fatigue, 102, pp. 18-36.

Skibicki, D., Pejkowski, Ł. (2012) Integral fatigue criteria evaluation for life estimation under uniaxial combined proportional and non-proportional loadings. Journal of Theoretical and Applied Mechanics, 50, 4, pp. 10731086.

Skibicki, D., Sempruch, J., Pejkowski, Ł. (2014) Model of non-proportional fatigue load in the form of block load spectrum. Materialwissenschaft und Werkstofftechnik, 45, 2, pp. 68-78.

Skibicki, D., Sempruch, J., Pejkowski, Ł. (2012) Steel X2CrNiMo17-12-2 Testing for Uniaxial, Proportional and Non-Proportional Loads as Delivered and in the Annealed Condition. Materials Science Forum, 726, pp. 171180. 